represents just a fraction of the total number of patients who paid handsomely for the stem-cell treatment for urinary incontinence without knowing it was experimental.

Strasser's department chair, Georg Bartsch, insists that he has no connection with, and no responsibility for, the scandal - despite having 'honorary authorship' on all the relevant papers, a practice that contravenes the university's code of practice. And Strasser himself has written an open letter to university authorities denying any wrongdoing.

At the beginning of July, a preliminary version of the report was circulated to those involved. Shortly afterwards, for reasons known only to itself, the university council announced plans to fire the university's respected rector, Clemens Sorg - who was going public with the problems - on grounds that many university and clinic officials believe to be invalid. Then the Austrian Academy of Sciences put its independent investigation, requested by Sorg, on hold. And on 13 August, the heads of the university hospital suddenly withdrew a letter of support for Sorg that they had sent out a few days earlier, saying they now realized it interfered with the university's internal affairs.

The council would be wise to think carefully before carrying out its threat to fire the rector under these conditions.

It seems clear that the academy of sciences is doing itself, and the community it represents, an inexcusable disservice by stepping back from helping to resolve a scandal of this magnitude. The academy claims, remarkably, to believe that Sorg asked for its help as an individual, not as the university's representative, and now that he may be dismissed, his concerns may similarly be dismissed - apparently on the grounds that the academy is an independent body. It would display its independence better by carrying forward its investigation into this shameful affair whether the person of the rector changes or not.

The academy is right in pointing out one thing, though. It may be morally responsible, but it is not legally responsible for addressing issues of scientific misconduct.
"There is no official body in Austria responsible for addressing issues of scientific misconduct."
There is no body in Austria with this remit. A few years ago, the ministry of research began discussions about creating a body similar to the US Office of Research Integrity or the Danish Committees on Scientific Dishonesty, but talks have so far come to nothing. Hopefully this affair will at least speed up this process.

It seems axiomatic that the chair of a university department must take responsibility for the goings-on in that department, and most certainly for any paper he or she co-authors. Any responses that the university makes to the report must take these factors into account whatever steps Bartsch takes to disassociate himself from the affair.

Austria is a small country, and networks between power-brokers are small and tight. But something, it seems, is rotten in the state of Austria, and it needs to be faced and dealt with openly.

\section{A case for nurture}

\section{Innovation is a complex ecosystem that requires careful cultivation.}

W

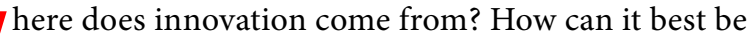
nurtured and encouraged? These questions are taking on global significance as fast-developing nations such as China, India and Brazil increasingly see leadership in innovation as key to their economic competitiveness. Although the link between innovation and economic strength is a matter for debate, the power of innovation to shape and transform society makes it worth studying. Earlier this summer, Nature began a monthly series of Commentaries to explore the origins of innovation and how it can be nurtured (see www.nature.com/nature/focus/innovation).

One common theme in the series is that the standard, linear model of innovation is too simplistic. That model, extant since at least the 1940 s, posits that new ideas and technologies originate in the nursery of basic research. And, like growing children moving through school and university to full-time employment, these innovations progress through applied research to development and, finally, to the marketplace.

This linear sequence contains an element of truth. But it misses the fact that many innovative ideas come the other direction: from users, consumers and efforts to solve practical problems. The linear model also tends to overstate the contribution that basic research makes to the final outcome, by neglecting the roles played by design, manufacturing and business processes. And the model tends to give policy-makers the impression that innovation is considerably more predictable and controllable than it actually is.

A more accurate picture is that of a nonlinear 'ecosystem', in which innovation is driven by multiple players, forces and feedback loops working simultaneously. Such an ecosystem cannot be managed - at least, not in the conventional sense of top-down control. But it can be cultivated, in the way that a gardener can try to create the right conditions for plants to grow, while accepting that unforeseen
"Scientists and engineers often feel hamstrung by the impositions of policy and regulation." elements ultimately dictate the outcome.

Such unpredictability is discussed on page 940 by David Guston, co-director of the Consortium for Science, Policy and Outcomes at Arizona State University in Tempe. The disruptive force of innovations, such as those edging their way towards fruition in stem-cell therapy, often seems at odds with a public policy that must consider the societal impacts of innovation and the social mores of the times. Scientists and engineers often feel hamstrung by the impositions of policy and regulation. Nevertheless, policies that nurture and guide innovation in socially acceptable frameworks could vastly increase public support and understanding of research goals.

The unpredictable nature of innovation means that this investment may not always turn out as expected. But with careful forethought, policy can usefully prepare the soil. This series of Commentaries will continue to explore the origin and nature of innovation - and, we hope, will provide powerful new ideas for culturing its growth. 